\title{
Obesity after Successful Treatment of Acute Lymphoblastic Leukemia in Childhood
}

\author{
J. E. W. M. VAN DONGEN-MELMAN, A. C. S. HOKKEN-KOELEGA, K. HÄHLEN, A. DE GROOT, \\ C. G. TROMP, AND R. M. EGELER \\ Department of Child and Adolescent Psychiatry [J.E.W.M.V.D.-M., A.D.G.], Department of Pediatrics, \\ Division of Endocrinology [A.C.S.H.-K.], and Department of Pediatrics, Division of Hematology/Oncology \\ [K.H., C.G.T., R.M.E.] Sophia Children's Hospital/Erasmus University, Rotterdam, The Netherlands
} \begin{abstract}
ABST
Early and late effects of treatment for acute lymphoblastic
leukemia (ALL) on weight was retrospectively investigated in 113 children in continuous first remission. Weight was examined at diagnosis up to $10 \mathrm{y}$ after cessation of treatment. There was an increased prevalence of overweight after treatment for ALL which persisted over time. All treatment regimens included corticosteroid therapy, and 52 patients received additional cranial irradiation. Patients treated with and without cranial irradiation did not differ in weight gain, indicating that not cranial irradiation but corticosteroid therapy might explain weight gain in children treated for ALL. Dexamethasone was associated with a significant increase of weight at cessation of treatment. Patients treated with a combination of prednisone and dexamethasone had
\end{abstract}

as a late effect the highest prevalence of obesity (44\%). Gender or age at diagnosis were not related to weight gain. (Pediatr Res 38: 86-90, 1995)

\section{Abbreviations}

ALL, acute lymphoblastic leukemia

BMI, body mass index

HR, high risk

NHR, non-high risk

MTX, methotrexate

MDMTX, moderate dose methotrexate

SDS, SD score

6-MP, 6-mercaptopurine
ALL is the most common type of leukemia in childhood and accounts for one fourth of all childhood cancers (1). It occurs in all races with a peak incidence in children between 3 and 5 $y$ of age. Now that the long-term survival rate has increased to $70 \%$, attention focuses on the refinement of treatment to decrease late sequelae in children. A number of late effects have been well documented including cardiotoxicity (2), dysfunction of liver (3), disorders in growth and puberty (4-6), second neoplasms (7), and emotional and neuropsychologic problems $(8,9)$. The adverse effects on weight gain in children treated for ALL is, however, less well documented. Obesity is not only a serious somatic problem, but it also affects the psychosocial adaptation of both long-term survivors (10) and their parents (11).

In a study on the late psychosocial effects of surviving childhood ALL (11), we observed a large proportion of obese patients. Others have confirmed that many survivors are overweight or obese (12-14). Obesity seems to be more pro-

Received December 16, 1994; accepted February 14, 1995.

Correspondence and reprint requests: R. M. Egeler, Department of Pediatrics, Division of Hematology/Oncology Sophia Children's Hospital, Dr. Molewaterplein 60, 3015 GJ Rotterdam, The Netherlands.

Supported by the Josephine Nefkens Foundation, the Integral Cancer Center Rotterdam, and the Rotterdam Childhood Cancer Center Foundation. nounced in girls (13). Furthermore, excessive weight gain has been observed especially during the first year after the cessation of anti-leukemic therapy (12). Most studies explain weight gain by cranial irradiation (12-14); however, others suggest that corticosteroid medication might be an important factor in the development of obesity (15-16).

We explored the weight of children treated for ALL up to $10 \mathrm{y}$ after cessation of treatment with or without cranial irradiation and with different modes of corticosteroid medication. The early and late effects of these treatment modalities on weight will be evaluated.

\section{METHODS}

Subjects. Patients diagnosed with ALL between 1978 and 1990 at the Sophia Children's Hospital Rotterdam were the subjects of this study. Inclusion criteria for the long-term analysis of obesity were 1 ) complete first remission for at least $2 \mathrm{y}$ after cessation of treatment and 2) no signs of CNS disease or constitutional chromosomal abnormality. For patients who relapsed after 2 y off therapy $(n=3)$, data collected only up to $1 \mathrm{y}$ before the date of relapse were included. For patients who were treated with growth hormone therapy $(n=4)$, respectively $5(n=1), 6(n=1)$, and $7 \mathrm{y}(n=2)$ after cessation of treatment, only data up to $1 \mathrm{y}$ before the date of endocrine 
therapy were included. All eligible patients $(n=113)$ were enrolled in the study. The sample consisted of 58 boys and 55 girls, median age at diagnosis $3 \mathrm{y}, 10$ mo (range: 6 mo to $15 \mathrm{y}$, $0 \mathrm{mo}$ ).

Patients were categorized into six groups according to treatment protocol: group 1, HR76; group 2, IIIB; group 3, V; group 4, VI pilot (VIp); group 5, VI; group 6, VII. Patients in group 1 had ALL with initial HR factors, defined as an initial white blood cell count $\geq 50 \cdot 10^{9} / \mathrm{L}$ and/or presence of mediastinal mass. Patients in groups $2-5$ were diagnosed as NHRALL. The treatment for groups $1-5$ had the same basic design of induction, followed by CNS treatment and maintenance therapy. Induction consisted of vincristine, corticosteroid, and (except in group 2) L-asparaginase. Children in group 3 were randomized for the addition of daunorubicin (17). In groups 1-3 CNS treatment consisted of 25-Gy cranial irradiation in 13 fractions plus 5 intrathecal injections of MTX delivered in 3 wk. In addition, children in group 1 received intrathecal MTX plus prednisolone once every $7 \mathrm{wk}$ for $1 \mathrm{y}$ (18). Children in groups 4 and 5 received three 24-h i.v. infusions of MDMTX in combination with intrathecal MTX and subsequently intrathecal triple therapy (MTX, cytarabine, prednisolone) once every $7 \mathrm{wk}$ for $1 \mathrm{y}$ (19). Maintenance treatment consisted of $5 \mathrm{wk}$ of daily 6-MP and weekly MTX, alternating with 2 wk of corticosteroid therapy and weekly vincristine. Children in group 2 received only 6-MP and MTX as maintenance. Corticosteroids were prednisone for the children in groups 1-4 or dexamethasone for those in group 5 (19). Total duration of chemotherapy was 3.25 y for group 1 and 2.25 y for groups $2-5$. Children in group 6 had HR or NHR-ALL. They were treated with a BFM-86-like protocol with, among others, MDMTX infusions as CNS treatment. No cranial irradiation was given. Prednisone was given during induction; dexamethasone during consolidation (20). Total duration of therapy for group 6 was $1.5 \mathrm{y}$. Protocols IIIB, V, VIp, VI, and VII were designed by the Dutch Childhood Leukemia Study Group. All protocols are summarized in Tables 1 and 2 .

Measures. Height and weight of patients were repeatedly measured by experienced staff. Data at diagnosis, cessation of treatment, and $1-y$ intervals thereafter up to $10 \mathrm{y}$ after cessation of treatment were used for this study. BMI was used as an index of obesity according to the formula weight/height ${ }^{2}$
$\left(\mathrm{W} / \mathrm{H}^{2}\right)(21)$. BMI-SD score (SDS) was computed for each patient at each time point with reference to the French population standard (i.e. reference group), taking into account changes in the variations of the distribution of BMI data in relation to age and sex (21).

Data analyses. To obtain estimates of early and late effects of treatment regimens on weight, values at time of diagnosis, cessation of treatment, and 4 y later were evaluated. This latter time point, 5.5-7.25 y from diagnosis, was chosen because all treatment groups had a sufficient number of patients. To compare the mean BMI-SDS at cessation of treatment and $4 \mathrm{y}$ later between the six treatment protocols, analyses of variance were used, $\mathrm{F}$ tests $(p<0.05)$. The same method of analysis was used to evaluate differences in weight between the separate components of treatment protocols, between both sexes, and different ages at diagnosis. To investigate if mean BMI-SDS differed significantly from zero, $t$ tests, one-tailed $(p<0.05)$ were applied. To establish the proportion of children with obesity, all children having BMI-SDS greater than 1.28 (above the 90 th percentile) were considered as obese.

\section{RESULTS}

There was considerable variability in weight scores among individual patients at each time point (Table 3). Between the six treatment protocols no statistical differences in mean BMISDS were found at cessation of treatment $(F=1.83, d f=5$, $p=0.11)$ or 4 y later $(F=0.76, d f=5, p=0.058)$. The prevalence of obesity at cessation of treatment and $4 \mathrm{y}$ later for the different treatment protocols indicate that a considerable proportion of survivors are overweight (Table 3). Children receiving treatment regimens that caused overweight $4 \mathrm{y}$ off therapy (Table 3: groups 1, 3, and 5) remained overweight thereafter (Fig. 1). For those protocols which could be evaluated up to 9 or $10 \mathrm{y}$ after cessation of treatment (groups 1-3), weights for children treated with cranial irradiation remained relatively stable (Fig. 1). Whereas weight gain in groups 1 and 2 remained clearly elevated; in group 3 weight gain remained moderate.

At diagnosis, in all treatment groups mean BMI-SDS were below the mean of the normal population (Fig. 1; Table 3). Of these groups, children in groups $1,4,5$, and 6 had weights that

Table 1. Treatment protocols for six groups of patients with ALL

\begin{tabular}{|c|c|c|c|c|c|c|c|c|c|c|c|c|c|}
\hline \multirow[b]{2}{*}{ Group } & \multirow[b]{2}{*}{ Protocol } & \multirow[b]{2}{*}{ Type ALL } & \multicolumn{3}{|c|}{ Induction } & \multicolumn{2}{|c|}{ CNS prophylaxis* } & \multicolumn{6}{|c|}{ Maintenance } \\
\hline & & & $\begin{array}{l}\text { VCR, } \\
\text { Pred, } \\
\text { L-asp }\end{array}$ & DNR & $\begin{array}{l}\text { VCR, } \\
\text { Dexa, } \\
\text { L-asp }\end{array}$ & $\begin{array}{l}\text { XRT, } \\
\text { MTX it }\end{array}$ & $\begin{array}{c}\text { MDMTX }{ }^{\dagger} \\
\text { MTX it }\end{array}$ & $\begin{array}{l}\text { VCR, } \\
\text { Pred }\end{array}$ & $\begin{array}{l}\text { VCR, } \\
\text { Dexa }\end{array}$ & $\begin{array}{l}\text { MTX } \\
\text { 6-MP }\end{array}$ & $\mathrm{CYC}$ & $\begin{array}{c}\text { MTX it, } \\
\text { Pred it }\end{array}$ & $\begin{array}{l}\text { MTX it, } \\
\text { Pred it, } \\
\text { ARA-C it }\end{array}$ \\
\hline 1 & HR & $\mathrm{HR}$ & + & - & - & + & - & + & - & + & + & + & - \\
\hline 2 & IIIB & NHR & $+\ddagger$ & - & - & + & - & - & - & + & - & - & - \\
\hline 3 & V & NHR & + & \pm & - & + & - & + & - & + & - & - & - \\
\hline 4 & VIp & NHR & + & - & - & - & + & + & - & + & - & - & - \\
\hline 5 & VI & NHR & - & - & + & - & + & - & + & + & - & - & + \\
\hline 6 & VII & $\mathrm{HR}+\mathrm{NHR}$ & + & + & - & - & + & - & + & + & + & - & + \\
\hline
\end{tabular}

VCR, vincristine; Pred, prednisone orally; Pred it, prednisone intrathecally; DNR, daunorubicine; Dexa, dexamethasone; L-asp, L-asparaginase; XRT, 25-Gy irradiation; it, intrathecally; CYC, cyclophosphamide; ARA-C, cytarabine.

* Induction plus CNS prophylaxis lasted 3 mo.

$\dagger \mathrm{MDMTX}=2 \mathrm{~g} / \mathrm{m}^{2} / 24$ h i.v. MTX.

$\ddagger$ No L-asp. 
Table 2. Cranial irradiation and corticosteroid therapy in treatment protocols for six groups of patients with ALL

\begin{tabular}{|c|c|c|c|c|c|c|c|c|}
\hline \multirow[b]{2}{*}{ Group } & \multirow[b]{2}{*}{ Protocol } & \multirow[b]{2}{*}{$n$} & \multirow[b]{2}{*}{$(\mathrm{M} ; \mathrm{F})$} & \multirow{2}{*}{$\begin{array}{c}\text { Cranial } \\
\text { irradiation } \\
(\mathrm{Gy})\end{array}$} & \multicolumn{4}{|c|}{ Corticosteroid therapy } \\
\hline & & & & & Type & $\begin{array}{l}\text { Duration } \\
\text { (wk) }\end{array}$ & $\begin{array}{c}\text { Dose } \\
\left(\mathrm{mg} / \mathrm{m}^{2} / \text { day }\right)\end{array}$ & $\begin{array}{c}\text { Total cumulative } \\
\text { dose }\left(\mathrm{mg} / \mathrm{m}^{2}\right)\end{array}$ \\
\hline 1 & HR76 & 16 & $(9 ; 7)$ & 25 & Pred & 49 & 40 & 13,720 \\
\hline 2 & IIIB & 5 & $(1 ; 4)$ & 25 & Pred & 5 & 40 & 1,400 \\
\hline 3 & V & 31 & $(18 ; 13)$ & 25 & Pred & 35 & 40 & 9,800 \\
\hline 4 & VIp & 13 & $(8 ; 5)$ & & Pred & 35 & 40 & 9,800 \\
\hline 5 & VI & 28 & $(15 ; 13)$ & & Dexa & 35 & 6 & 1,470 \\
\hline 6 & VII & 20 & $(10 ; 10)$ & & Pred/Dexa & $5 / 4$ & $60 / 10$ & $2,100 / 280$ \\
\hline
\end{tabular}

Pred, prednisone orally; Dexa, dexamethasone orally; $M=$ male; $F=$ female.

Table 3. Percentage of obese children $(>p 90)$, mean BMI-SDS scores, and standard deviations for the six treatment protocols at cessation of treatment and 4 y later

\begin{tabular}{|c|c|c|c|c|c|c|c|c|c|c|c|}
\hline \multirow[b]{2}{*}{ Group } & \multirow[b]{2}{*}{ Protocol } & \multirow[b]{2}{*}{$n$} & \multicolumn{3}{|c|}{ Diagnosis } & \multicolumn{3}{|c|}{ Cessation of treatment } & \multicolumn{3}{|c|}{$4 \mathrm{y}$ after cessation of treatment } \\
\hline & & & $\%$ & Mean SDS & $\mathrm{SD}$ & $\%$ & Mean SDS & SD & $\%$ & Mean SDS & $\mathrm{SD}$ \\
\hline 1 & HR76 & 16 & $6(n=1)$ & $-0.52 *$ & 1.00 & $38(n=6)$ & $0.85^{*}$ & 1.54 & $27(n=4)$ & $1.00^{*}$ & 1.29 \\
\hline 2 & IIIB & 5 & $0(n=0)$ & -0.23 & 0.69 & $20(n=1)$ & 0.00 & 1.57 & $25(n=1)$ & 0.24 & 1.62 \\
\hline 3 & $\mathrm{~V}$ & 31 & $10(n=3)$ & -0.42 & 1.37 & $32(n=10)$ & $0.62^{*}$ & 1.38 & $31(n=9)$ & $0.89^{*}$ & 1.42 \\
\hline 4 & VIp & 13 & $8(n=1)$ & $-0.76^{*}$ & 1.62 & $15(n=2)$ & 0.62 & 1.22 & $17(n=2)$ & 0.61 & 1.46 \\
\hline 5 & VI & 28 & $11(n=3)$ & $-0.37^{*}$ & 1.07 & $43(n=12)$ & $1.34 *$ & 1.60 & $26(n=7)$ & $0.74^{*}$ & 1.45 \\
\hline 6 & VII & 20 & $5(n=1)$ & $-0.71^{*}$ & 1.22 & $15(n=3)$ & 0.03 & 1.14 & $44(n=4)$ & $1.40^{*}$ & 1.48 \\
\hline
\end{tabular}

* Significantly different from zero $(t$ test, $p<0.05)$.

were significantly below zero. At cessation of treatment all treatment groups had gained weight. Patients in groups 1, 3, and 5 had significantly higher mean BMI-SDS than the reference group, showing a prevalence of obesity of, respectively, 38,32 , and $43 \%$. At this time point most obese children were found in group 5, which included 35 wk of dexamethasone medication without cranial irradiation. Treatment used in group 2 (5 wk of prednisone medication with cranial irradiation) was least associated with short-term weight gain. Four years later, 5.25-7 y from diagnosis, all mean BMI-SDS were still above the mean of the reference group. At this time point mean BMI-SDS of children in groups $1,3,5$, and 6 were significantly above zero. In these treatment groups, respectively, 27, 31, 26, and $44 \%$ of the children were obese. Children in group 2 continued to have lowest weight scores.

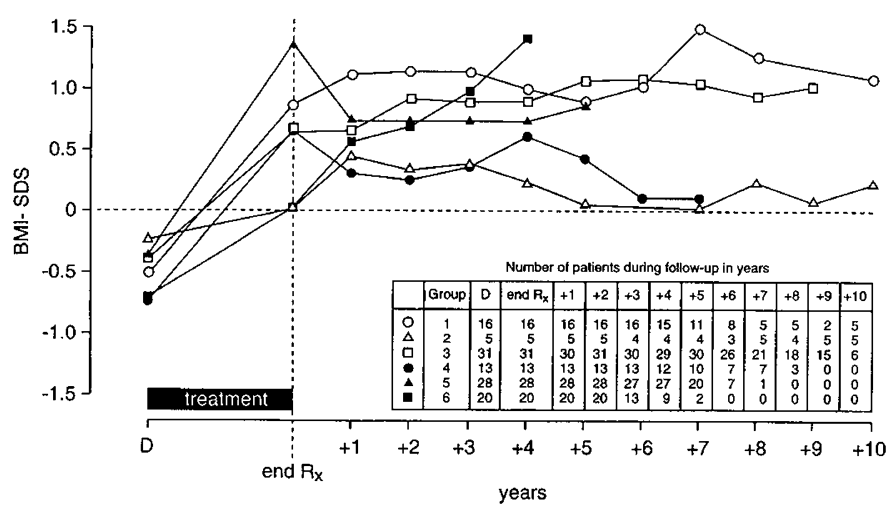

Figure 1. BMI-SD scores (SDS) in 113 children up to $13 \mathrm{y}$ from ALL diagnosis. Time points for the different treatment protocols were excluded in the figure if $<30 \%$ of patients were evaluated or if data were obtained from $\leq 3$ patients. Open symbols, treatment regimens with cranial irradiation; closed symbols, treatment regimens without cranial irradiation; $D$, diagnosis; $R_{x}$, treatment.
Effect of treatment factors, gender, and age at diagnosis on weight. At cessation of treatment and $4 \mathrm{y}$ later, the effect of cranial irradiation (yes, no), corticosteroid therapy (prednisone orally, dexamethasone, both), cumulative dose of prednisone orally $(1,400,9,800$, and $13,720 \mathrm{mg})$, gender (boys, girls), and age at diagnosis $(0-2 \mathrm{y}, 2-6 \mathrm{y}, 6-12 \mathrm{y}, 12-15 \mathrm{y})$ on BMI-SDS was investigated. Results are summarized in Table 4.

Cranial irradiation did not have an effect on weight scores at cessation of treatment or 4 y later. Comparison between protocols with the same cumulative dose of prednisone $(9800 \mathrm{mg}$ ) but with or without cranial irradiation (group 3 versus group 4) showed no difference in mean BMI-SDS at cessation of treatment $(F=0.000, d f=1, p=0.99)$ nor 4 y later $(F=0.313$, $d f=1, p=0.60$ ). With respect to corticosteroid therapy, type of medication did have an effect on weight gain. At cessation of treatment, children who had received dexamethasone were more obese than children who had received prednisone or both corticosteroids. Four years later, the effect of dexamethasone had dissipated compared with that of other types of medication. Differences between the three types of therapy were not significant, although all children remained overweight in comparison to the reference group. At this time point, children enrolled in group 6 , treated with a combination of dexamethasone and prednisone without cranial irradiation, were most obese (44\%). The effect of cumulative dose was investigated only in children receiving prednisone therapy. A higher cumulative dose of prednisone was associated with higher BMI-SDS. This finding was consistent at cessation of treatment and 4 y later; however, differences did not reach statistical significance.

There were no differences in mean BMI-SDS between boys and girls at diagnosis $(F=0.000, d f=1, p=0.94)$, cessation of treatment, and $4 \mathrm{y}$ later. We investigated if there was a difference in sensitivity of boys or girls for type of therapy. On both time points $(F=1.3, d f=1, p=0.25$ and $F=0.23$, 
Table 4. Percentage of obese children $(>p 90)$ and mean BMI-SDS in relation to cranial irradiation, corticosteroid therapy, cumulative dose, gender, and age at diagnosis

\begin{tabular}{|c|c|c|c|c|c|c|c|c|c|c|c|}
\hline \multirow[b]{2}{*}{ Treatment component } & \multirow[b]{2}{*}{$n$} & \multicolumn{5}{|c|}{ Cessation of treatment } & \multicolumn{5}{|c|}{$4 \mathrm{y}$ after cessation of treatment } \\
\hline & & $\%$ & Mean SDS & $\mathrm{F}$ & $d f$ & $p$ & $\%$ & Mean SDS & $\mathrm{F}$ & $d f$ & $p$ \\
\hline \multicolumn{12}{|l|}{ Cranial irradiation } \\
\hline Yes & 52 & $33(n=17)$ & $0.63^{*}$ & 0.00 & 1 & 0.96 & $29(n=14)$ & $0.83^{*}$ & 0.38 & 1 & 0.54 \\
\hline No & 61 & $28(n=17)$ & $0.75^{*}$ & & & & $27(n=13)$ & $0.87^{*}$ & & & \\
\hline \multicolumn{12}{|l|}{ Corticosteroid therapy } \\
\hline Pred & 65 & $29(n=19)$ & $0.63^{*}$ & & & & $27(n=16)$ & $0.82^{*}$ & & & \\
\hline Dexa & 28 & $43(n=12)$ & $1.34^{*}$ & 4.52 & 2 & 0.01 & $26(n=7)$ & $0.74^{*}$ & 1.05 & 2 & 0.36 \\
\hline Pred and Dexa & 20 & $15(n=3)$ & 0.03 & & & & $44(n=4)$ & $1.40^{*}$ & & & \\
\hline \multicolumn{12}{|l|}{ Cumulative dose Pred $\dagger$} \\
\hline $1,400 \mathrm{mg}$ & 5 & $20(n=1)$ & 0.00 & & & & $25(n=1)$ & 0.24 & & & \\
\hline $9,800 \mathrm{mg}$ & 44 & $27(n=12)$ & $0.62^{*}$ & 0.71 & 2 & 0.50 & $27(n=11)$ & $0.81^{*}$ & 0.47 & 2 & 0.63 \\
\hline $13,720 \mathrm{mg}$ & 16 & $38(n=6)$ & $0.85^{*}$ & & & & $27(n=4)$ & $1.00^{*}$ & & & \\
\hline \multicolumn{12}{|l|}{ Gender } \\
\hline Boys & 58 & $35(n=20)$ & $0.82^{*}$ & 0.62 & 1 & 0.43 & $28(n=14)$ & $0.79 *$ & 0.41 & 1 & 0.52 \\
\hline Girls & 55 & $26(n=14)$ & $0.57^{*}$ & & & & $28(n=13)$ & $0.92 *$ & & & \\
\hline \multicolumn{12}{|l|}{ Age at diagnosis } \\
\hline$\leq 2 \mathrm{y}$ & 10 & $40(n=4)$ & $0.94^{*}$ & & & & $20(n=2)$ & $0.76^{*}$ & & & \\
\hline $2-6 y$ & 71 & $32(n=23)$ & $0.81^{*}$ & 1.45 & 3 & 0.23 & $32(n=19)$ & $0.92 *$ & 0.48 & 3 & 0.70 \\
\hline $6-12 y$ & 22 & $14(n=3)$ & 0.08 & & & & $17(n=3)$ & 0.57 & & & \\
\hline$>12 y$ & 10 & $40(n=4)$ & $1.01^{*}$ & & & & $38(n=3)$ & $1.10^{*}$ & & & \\
\hline
\end{tabular}

Pred, prednisone orally; Dexa, dexamethasone orally.

* Significantly different from zero $(t$ test, $p<0.05$ ).

$\dagger$ Group 5 and 6 (protocol VI and VII) excluded from analysis.

$d f=1, p=0.63$ ) mean BMI-SDS of patients treated with or without cranial irradiation were not significantly different for boys or girls. Although at cessation of treatment $43 \%$ of the irradiated boys were obese versus $21 \%$ of the girls, this difference had disappeared (27\% versus $31 \%$ ) 4 y later. For prednisone, dexamethasone, and both types of medication, mean BMI-SDS did not significantly differ between boys and girls at cessation of treatment $(F=1.53, d f=3, p=0.22)$ and $4 \mathrm{y}$ later $(F=0.64, d f=2, p=0.53)$, although prevalence of obesity did differ for boys and girls. At cessation of treatment $40 \%$ of the boys treated with prednisone were obese versus $19 \%$ of the girls. Furthermore, at that time point boys seemed somewhat more sensitive for dexamethasone, resulting in $47 \%$ obesity versus $39 \%$ for girls. Differences in obesity between boys and girls were smaller 4 y later. Boys and girls were most affected by the combination of prednisone and dexamethasone, causing, respectively, 40 and $50 \%$ of these children to be obese.

Age at diagnosis did not have a significant effect on mean BMI-SDS at cessation of treatment or 4 y later. After cessation of treatment, $40 \%$ of the youngest and oldest children were obese. Four years later, still $38 \%$ of the oldest children were overweight.

\section{DISCUSSION}

The improved survival of children with ALL has focused attention on the late effects of anti-leukemic therapy. This retrospective study, representing one of the largest single institutional series on weight of patients surviving ALL, clearly showed that obesity is a late effect for children successfully treated for ALL. Weight gain started during treatment and persisted after cessation of treatment. For treatment regimens that caused significant overweight after cessation of treatment and which could be evaluated up to $10 \mathrm{y}$ after cessation of treatment (groups 1, 3, and 5), mean BMI-SDS did not return to normal values. Our study gives insight into factors which may account for an increase in weight.

It has been suggested that cranial irradiation may cause damage to the hypothalamic-pituitary axis, inducing a decrease in growth and lipolysis which may result in obesity $(5,6$, 12-14). In contrast, our study clearly demonstrated that protocols with cranial irradiation (groups 1, 2, and 3) did not induce more weight gain than those without cranial irradiation (groups 4,5 , and 6). In fact, protocols with the highest prevalence of obesity at cessation of treatment and 4 y later were those with corticosteroids and without irradiation. This finding implies that the use of corticosteroid therapy has more dominant effect on weight gain than irradiation-induced pituitary dysfunction. Previous studies were not able to test the effect of corticosteroids because no or only small numbers of nonirradiated patients were included (12-16). Another complication in evaluating the effect of irradiation is the use of control groups consisting of children treated for other malignancies (13). Although these groups control for the factor irradiation, they do not control for differences in corticosteroid therapy.

Our study showed that corticosteroid therapy, in particular protocols with dexamethasone, was associated with obesity as an early and late side effect. At cessation of treatment, children who received dexamethasone were more obese than children who received dexamethasone in addition to prednisone. This finding is probably explained by the fact that children on both steroids had a lesser total dose of dexamethasone overall. There was a tendency that a higher cumulative dose of prednisone was related to a higher increase in weight. It has been observed that children during induction chemotherapy receiving high doses of corticosteroids gain weight rapidly (15). 
Continuous use of corticosteroids given as recurrent short pulses throughout maintenance therapy can have a persistent effect on weight gain as observed in our study at cessation of treatment. It remains unclear why this increase in weight continues long after treatment is stopped. One explanation for the continuing increase in weight long after the cessation of therapy would be the development of sequential endocrinopathies.

It has been suggested that impaired growth and short stature is a major contribution to the obesity in survivors of childhood cancer (14). The BMI formula $\left(\mathrm{W} / \mathrm{H}^{2}\right)$ is, however, a measure which is used for its insensitivity to height (12). Also psychosocial factors are mentioned to explain an increase in weight $(15,16)$. Although this may play a role, it seems unlikely that these may have caused the effect. If these factors play a role, children in all treatment groups would be equally affected and thus no differences in weight gain between treatment regimens would be observed. Furthermore, it has been reported that the body composition is different in long-term survivors of ALL compared with healthy children $(22,23)$ which may point more to somatic than psychosocial factors.

An alternative explanation for weight gain after successful treatment of ALL in childhood is that CNS prophylaxis per se might be responsible for weight gain. All children have received CNS prophylaxis. Thus, cranial irradiation or intensive intrathecal therapy which invariably accompanies corticosteroid therapy might cause an increase in weight. However, children's weight after having received protocols used in group 2 or group 4 with CNS prophylaxis consisting of, respectively, cranial irradiation plus intrathecal MTX or MDMTX plus intrathecal MTX at cessation of treatment and $4 \mathrm{y}$ later was not different from the reference group. Moreover, children treated with these protocols reached near normal values $7 \mathrm{y}$ after cessation of treatment. Although this finding may lend support to the role of corticosteroids in weight gain, it should be noticed that in both treatment groups the number of patients was small.

In contrast to a study in 40 survivors (13), we found no differences in increase of weight between boys and girls. In another study including a large number of patients, sex was also not associated with fatness (12). Therefore, gender differences in weight gain sensitivity to treatment may be an artifact due to the limited number of patients included in a study.

Our study showed that obesity is an early and a late side effect of anti-leukemic therapy. Further prospective studies are needed to elucidate the role of corticosteroids and type of CNS prophylaxis in weight gain. This implies that weight needs to be carefully monitored in large number of patients. As shown, patterns of obesity of a particular treatment regimen can vary over time. Consequently, studies are necessary that monitor weight of former patients over a prolonged period of time, preferably into adulthood. Even after $10 \mathrm{y}$ from cessation of treatment, we found in a small subsample of patients an increase of weight. In addition, other measures than weight should be taken into account, such as endocrine status (e.g. growth hormone therapy), fat distribution, body composition, and energy expenditure which may further clarify mechanisms for this late effect of cancer treatment (13). Hopefully this provides guidelines for managing overweight in children successfully treated for ALL.

Acknowledgment. We thank Dr. A. van Teunenbroek, Department Endocrinology, for his support.

\section{REFERENCES}

1. Pui CH, Crist WM 1994 Biology and treatment of acute lymphoblastic leukemia. J Pediatr 124:491-503

2. Lipschultz SE, Colan SD, Gelber RD, Perez-Atayde AR, Sallan SE, Sanders SP 1991 Late cardiac effects of doxorubicin therapy for acute lymphoblastic leukemia in childhood. N Engl J Med 324:808--815

3. Chessels JM 1983 Childhood acute leukaemia: The late effects of treatment. $\mathrm{Br} J$ Haematol 53:369--378

4. Hokken-Koelega ACS, Van Doorn JWD, Hählen K, Stijnen T, De Muinck KeizerSchrama SMPF, Drop SLS 1993 Long-term effects of treatment for acute lymphoblastic leukemia with and without cranial irradiation on growth and puberty: comparative study. Pediatr Res 33:577-582

5. Clayton PE, Shalet SM, Morris-Jones PH, Price DA 1988 Growth in children treated for acute lymphoblastic leukaemia. Lancet 1:460-462

6. Shalet SM, Clayton PE, Price DA 1988 Growth and pituitary function in children treated for brain tumours or acute lymphoblastic leukaemia. Horm Res 30:53-61

7. Neglia JP, Meadows AT, Robinson LL, Kim TH, Newton WA, Ruymann FB, Sather HN, Hammond GD 1991 Second neoplasms after acute lymphoblastic leukemia in childhood. N Engl J Med 325:1330-1336

8. Jankovic J, Brouwers P, Valsecchi MG, Van Veldhuizen A, Huisman J, Kamphuis R, Kingma A, Mor W, Van Dongen-Melman J, Feronato L, Mancini MA, Spinetta JJ, Masera G 1994 Association of $1800 \mathrm{cGy}$ cranial irradiation with intellectual function in children with acute lymphoblastic leukemia. Lancet 334:224-227

9. Koocher GP, O'Malley JE 1981 The Damocles Syndrome. McGraw Hill, New York

10. Van Dongen-MeIman JEWM, De Groot A, Hählen K, Verhulst FC 1994 Psychosocial functioning of children who survived cancer. Med Pediatr Oncol 23:297

11. Van Dongen-Melman JEWM, Pruyn JFA, De Groot A, Koot HM, Hählen K, Verhulst FC Late consequences for parents of children who survived cancer. J Pediatr Psychol (in press)

12. Zee P, Chen C-H 1986 Prevalence of obesity in children after therapy for acute lymphoblastic leukemia. Am J Pediatr Hematol/Oncol 8:294-299

13. Odame I, Reilly JJ, Gibson BES, Donaldson MDC 1994 Patterns of obesity in boys and girls after treatment for acute lymphoblastic leukaemia. Arch Dis Child 71:147149

14. Shell MJ, Ochs, JJ, Schriock EA, Carter M 1992 A method of predicting adult height and obesity in long-term survivors of childhood acute lymphoblastic leukemia. J Clin Oncol 10:128-133

15. Sainsbury CPQ, Newcombe RG, Hughes IA 1985 Weight gain and height velocity during prolonged first remission from acute lymphoblastic leukaemia. Arch Dis Child 60:832-836

16. Tamminga RYJ, Kamps WA, Drayer NM, Humphrey GB 1992 Longitudinal anthropometric study in children with acute lymphoblastic leukaemia. Acta Paediatr 81:61-65

17. Van der Does-Van den Berg A, Van Wering ER, Suciu S, Solbu G, Van't Veer MB, Rammeloo JA, De Koning J, Van Zanen GE 1989 Effectiveness of rubidomycin in induction therapy with vincristine, prednisone, and L-asparaginase for standard risk childhood acute lymphoblastic leukemia: Results of a Dutch phase III study (ALL V). Am J Pediatr Oncol/Hematol 11:125-133

18. Hooijkaas H, Hählen K, Adriaansen HJ, Dekker I, Van Zanen GE, Van Dongen JJM 1989 Terminal deoxynucleotidyl transferase (TDT)-positive cells in cerebrospinal fluid and development of overt CNS leukemia: A 5 year follow-up study in 113 children with TdT-positive leukemia and non-Hodgkin's lymphoma. Blood 74:416422

19. Veerman AJ, Hählen K, Kamps WA, Van Leeuwen EF, De Vaan GAM, Van Wering ER, Van der Does-Van den Berg A, Solbu G, Suciu S 1990 Dutch Childhood Leukemia Study Group: Early Results of study ALL VI (1984-1988). Haematol Blood Transfus 33:1437-1477

20. Riehm H, Gadner H, Henze G, Kornhuber B, Lampert F, Niethammer D, Reiter A, Schellong G 1990 Results and significance of six randomized trials in four consecutive ALL-BFM studies. Hematol Blood Transfus 33:439-450

21. Rolland-Cachera AF, Sempé M, Guilloud-Bataille M, Patois E, PéquignotGuggenbuhl F, Fautrad V 1982 Adiposity indices in children. Am J Clin Nutr 36:178-184

22. Starceski PJ, Lee PA, Blatt J, Finegold D, Brown D 1987 Comparable effects of 1800and 2400-rad (18- and 24-Gy) cranial irradiation for height and weight in children treated for acute lymphocytic leukemia. Am J Dis Child 141:550-552

23. Armbrust W, Tamminga RYJ, Kamps WA 1994 Body composition after treatment for acute lymphoblastic leukemia. Med Pediatr Oncol 23:274 